Check for updates

Cite this: J. Mater. Chem. C, 2020 8, 16436

Received 9th September 2020, Accepted 18th October 2020

DOI: $10.1039 / \mathrm{d0tc04310a}$

rsc.li/materials-c

\section{Multiscale understanding of electric polarization in poly(vinylidene fluoride)-based ferroelectric polymers $\uparrow$}

\author{
Nan Meng, (D) ${ }^{a b}$ Xintong Ren, (D) ${ }^{b}$ Xiaojing Zhu, (D ${ }^{b}$ Jiyue Wu, (D) bin Yang, (D) *c \\ Feng Gao, (iD d Han Zhang, (iD b Yaozu Liao, (iD a Emiliano Bilotti, id b \\ Michael J. Reece ${ }^{b}$ and Haixue Yan (D) *b
}

\begin{abstract}
Poly(vinylidene fluoride) (PVDF) and PVDF-based copolymers with trifluoroethylene (PVDF-TrFE) have attracted considerable academic and industrial interest due to their ferroelectric properties, which are only present in very few polymers. However, the underlying fundamentals of molecular ordering and induced polarizations are complex and not fully understood. Herein, PVDF, PVDF-TrFE and their blends, prepared using melt extrusion and hot pressing, have been selected to obtain controlled case studies with welldefined chain ordering and microstructures. Impedance analysis and terahertz time-domain spectroscopy (THz-TDS) are exploited to investigate electric polarization in PVDF-based polymers at different length scales. The extruded ferroelectric films show in-plane chain orientation and higher domain wall density compared to hot pressed films with randomly-distributed polymer chains, which favors the polarization at low frequencies $(\mathrm{Hz}$ to $\mathrm{MHz}$ ), as concluded from the higher dielectric constants and more prominent high electric field polarization switching features. However, the domain walls cannot respond at high frequencies, which leads to lower dielectric constants in the extruded films at $\mathrm{THz}$ frequencies.
\end{abstract}

\section{Introduction}

Poly(vinylidene fluoride) (PVDF) based polymers are candidate materials for applications in sensors and actuators, ${ }^{1,2}$ energy harvesting and storage ${ }^{3-5}$ and non-volatile memory devices ${ }^{6,7}$ because of their good dielectric, piezoelectric and ferroelectric properties. PVDF exhibits a complex structure with multiple crystalline polymorphs ( $\alpha$-, $\beta$-, $\gamma$ - and $\delta$-phase) along with the existence of amorphous regions arising from its semi-crystalline nature. The crystallographic data and the spontaneous polarization $\left(P_{\mathrm{s}}\right)$ calculated using a model of rigid dipoles for the different crystalline phases are summarized in Table $1 .^{8,9}$ Of the four crystalline forms, the $\alpha$-phase is non-polar due to the self-cancellation of dipoles arising from antiparallel adjacent chain packing,

\footnotetext{
${ }^{a}$ State Key Laboratory for Modification of Chemical Fibers and Polymer Materials, College of Materials Science and Engineering, Donghua University, Shanghai, 201620, P. R. China

${ }^{b}$ School of Engineering and Materials Science, Queen Mary University of London, Mile End Road, London E1 4NS, UK. E-mail: h.x.yan@qmul.ac.uk ${ }^{c}$ Department of Computer Science, Electronic and Electrical Engineering, Faculty of Science and Engineering, University of Chester, Thornton Science Park, $\mathrm{CH} 24 \mathrm{NU}$, UK. E-mail: b.yang@chester.ac.uk

${ }^{d}$ State Key Laboratory of Solidification Processing, School of Materials Science and Engineering, NPU-QMUL Joint Research Institute of Advanced Materials and Structure, Northwestern Polytechnical University, Xi'an, 710072, P. R. China

$\dagger$ Electronic supplementary information (ESI) available. See DOI: 10.1039/d0tc04310a
}

while the other three structures are polar. The $\beta$-phase shows the highest dipole moment $\left(\mu=7 \times 10^{-30} \mathrm{C} \mathrm{m}\right)$ perpendicular to the chain axis ( $c$-axis) and the best ferroelectric performance ${ }^{9}$ with a $P_{\mathrm{s}}$ of $0.13 \mathrm{C} \mathrm{m}^{-2}$. PVDF crystallizes into the $\alpha$-phase when cooled from the melt. The $\beta$-phase is usually obtained after post-treatments of the as-formed $\alpha$-phase, like solid-state drawing, ${ }^{8}$ solid-state pressure deformation $^{10}$ and/or electric field poling $\left(>500 \mathrm{kV} \mathrm{mm}{ }^{-1}\right){ }^{8}$ Poling at relatively low electric fields $\left(\sim 170 \mathrm{kV} \mathrm{mm}^{-111,12}\right)$ can only transform the $\alpha$-phase into the $\delta$-phase. The $\gamma$-phase is usually obtained via solvent crystallization, ${ }^{13}$ or via re-crystallization at temperatures slightly above melting point ${ }^{14}$ or via the addition of fillers such as carbon-based materials. ${ }^{15}$

To achieve better dielectric and ferroelectric properties, the fundamental physics of crystalline polymorphism, dipole rotation and macroscopic ordering of molecules still need to be clarified. The anisotropy of the polarizability of PVDF-based materials at low frequencies ( $\mathrm{Hz}$ to $\mathrm{MHz}$ ) has been well studied, ${ }^{16-20}$ where films with in-plane distribution of polymer chains ( $c$-axis) show relatively high dielectric constant (11-14 at $100 \mathrm{~Hz}$ ) and low coercive field (30-70 kV mm ${ }^{-1}$ measured at $10 \mathrm{~Hz}$ ), compared to films with randomly distributed polymer chains (dielectric constant: 7; coercive field: $260 \mathrm{kV} \mathrm{mm}{ }^{-1}$ ), since the $\mathrm{CH}_{2}-\mathrm{CF}_{2}$ dipoles can respond easily to an applied external electric field. However, the dielectric polarization of PVDF-based polymers at high frequencies of terahertz ( $\mathrm{THz}$ or $10^{12} \mathrm{~Hz}$ ) arising from the contribution of local 
Table 1 Crystallographic data and spontaneous polarization of PVDF with different crystalline phases. ${ }^{8,9}$

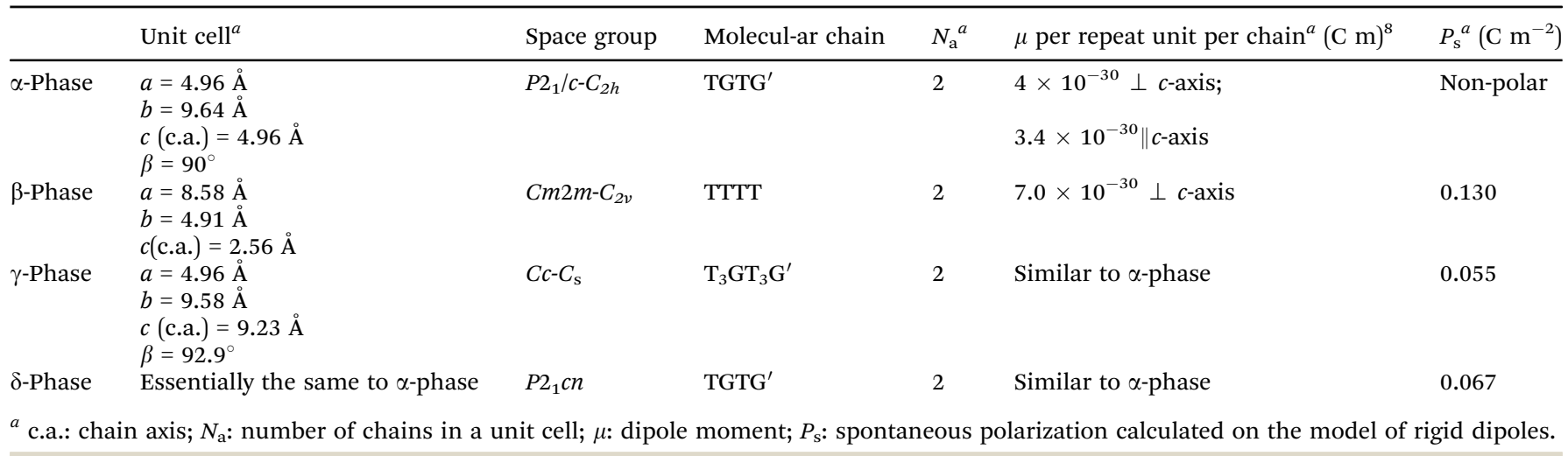

structures is rarely characterized and thereby not fully understood. The coherent terahertz time-domain spectroscopy (THz-TDS) can be implemented to detect the collaborative motions of large molecules, for instance, the intramolecular and/or intermolecular vibrations of polymer chains with molecular weights exceeding several hundreds of atomic mass units (equivalent to $\mathrm{g} \mathrm{mol}^{-1}$ ). ${ }^{2-23}$ Accordingly, in this work, the THz-TDS spectroscopy combined with impedance analysis was utilized to characterize the real part of the dielectric permittivity and loss tangent and investigate the structural dependence of dielectric properties. Three different polymeric materials have been studied - PVDF, PVDF-TrFE and their blends with a mass ratio of 50/50 - as well as different processing methods - melt extrusion and hot pressing, which enabled the tailoring of chain ordering and microstructures.

\section{Experimental}

\section{Film preparation}

The PVDF (average molecular weight $530 \mathrm{~kg} \mathrm{~mol}^{-1}$ ) and PVDFTrFE (molar ratio of VDF/TrFE 75/25) used in this work were purchased from Sigma Aldrich Chemical Co and PiezotechArkema, respectively. The extruded PVDF (melting temperature: $\sim 160{ }^{\circ} \mathrm{C}$ ) and PVDF-TrFE (melting temperature: $\sim 150{ }^{\circ} \mathrm{C}$ ) films were prepared using a Xplore Micro compounder MC-15-HT (Xplore Instruments BV, The Netherlands). They were extruded at $200{ }^{\circ} \mathrm{C}$ and $190{ }^{\circ} \mathrm{C}$, respectively, and collected at room temperature with a film die of $200 \mu \mathrm{m}$ thickness. The extruded blends of PVDF/PVDF-TrFE 50/50 wt $\%$ were also extruded at $200{ }^{\circ} \mathrm{C}$. The hotpressed PVDF and PVDF-TrFE films were compression molded at $200{ }^{\circ} \mathrm{C}$ and $180^{\circ} \mathrm{C}$, respectively, for 5 minutes using a Collin hot press P300E (COLLIN Lab \& Pilot Solutions GmbH, Germany). The hot-pressed blends were also prepared at $200{ }^{\circ} \mathrm{C}$ for 5 minutes. The pellets of PVDF/PVDF-TrFE 50/50 wt\% were firstly extruded into strands before cutting into pellets.

\section{Structure characterization}

X-ray diffraction (XRD, X'Pert Pro, PANalytical, Almelo, The Netherlands) in the $2 \theta$ range of $5-70^{\circ}$ with $\mathrm{Cu} / \mathrm{K} \alpha(\lambda=$ $0.15418 \mathrm{~nm}$ ) radiation was used to characterize the crystalline polymorphs. Differential scanning calorimetry (DSC, DSC 25, TA Instruments, Asse, Belgium) with a temperature range of
25-200 ${ }^{\circ} \mathrm{C}$ and a heating rate of $10{ }^{\circ} \mathrm{C} \mathrm{min}^{-1}$ was used to analyse the thermal properties. Fourier-transform infrared spectroscopy (FTIR) (Tensor 27, Bruker Optik GmbH, Ettlingen, Germany) was used to complement and validate the phase identification of the polymer films both qualitatively and quantitatively. The preferred orientation of the polymer chains was characterized using twodimensional X-ray diffraction (2D-XRD) ring patterns (Kappa ApexII Duo, Bruker AXS GmbH, Karlsruhe, Germany), which were obtained using $\mathrm{Cu} / \mathrm{K} \alpha(\lambda=0.15418 \mathrm{~nm})$ radiation with the incident beam normal to the surface of polymer samples. The morphology of film surface was characterized using scanning electron microscopy (SEM) (FEI Inspector-F, The Netherlands).

\section{Ferroelectric and dielectric properties measurement}

The ferroelectric properties were tested using a triangle waveform at a frequency of $10 \mathrm{~Hz}$ on a ferroelectric hysteresis tester (NPL, Teddington, UK) with a maximum applied voltage of $10 \mathrm{kV} \cdot{ }^{24}$ Electrodes were prepared using gold sputtering with a diameter of $2 \mathrm{~mm}$. The frequency dependent dielectric permittivity in the range of $100 \mathrm{~Hz}$ to $100 \mathrm{MHz}$ was measured using an impedance analyzer (4294A, Agilent, Santa Clara, CA) with an applied voltage of $0.5 \mathrm{~V}$ at room temperature. The THz-TDS spectra (TeTechS Ltd, Ontario, Canada) were measured using a transmission mode from $0.5 \mathrm{THz}$ to $2 \mathrm{THz}$ at room temperature with an extremely low humidity $<0.3 \%$, controlled through a nitrogen purge. The parameter extraction involves a transmitted Fourier transformed pulse waveform recording the temporal response of the THz reference pulse as a function of time delay. More details about the set-up of THz-TDS can refer to our previous work. ${ }^{25}$

\section{Results and discussion}

\section{Structure determination}

Fig. 1 shows the structural characterization for the films using X-ray diffraction (XRD) and differential scanning calorimetry (DSC). PVDF films mainly crystallize into $\alpha$-phase, as concluded from the presence of peaks at $17.8^{\circ}, 18.4^{\circ}$ and $20.0^{\circ}$, resulting from the reflections of $(100)_{\alpha-\mathrm{PVDF}},(020)_{\alpha-\mathrm{PVDF}}$ and $(110)_{\alpha-\mathrm{PVDF}}$, respectively, and the absence of $\beta$-phase characteristic peaks at $20.8^{\circ}(110) /(200)_{\beta \text {-PVDF }}$ and $36.5^{\circ}(020) /(101)_{\beta \text {-PVDF }}$ (Fig. 1a). ${ }^{26}$ The PVDF-TrFE films show strong peaks assigned to the reflections 

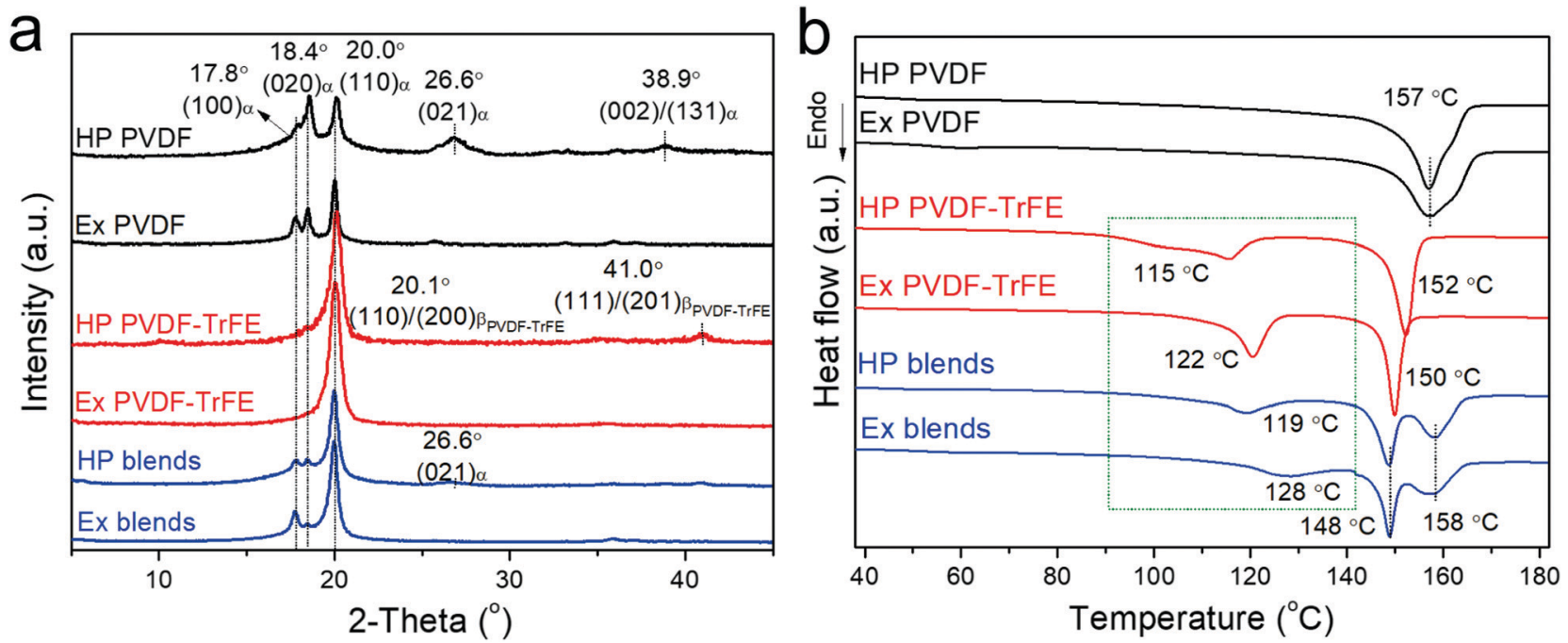

Fig. 1 Structural characterization of films processed via melt-extrusion (Ex) and hot-compression (HP): (a) XRD and (b) DSC.

of $(110) /(200)_{\beta-P V D F-T r F E}$, which is at a lower angle of $20.0^{\circ}$ compared to $20.8^{\circ}$ of $\beta$-PVDF due to the enlarged inter-chain lattice spacing arising from the incorporation of another large fluorine atom in the TrFE unit. $^{27}$ The blends of PVDF/PVDF-TrFE 50/50 $\mathrm{wt} \%$ exhibit superimposed peaks at $17.8^{\circ}, 18.4^{\circ}$ and $20.0^{\circ}$, which confirms the presence of both $\alpha$ - and $\beta$-phase. Fourier-transform infrared spectroscopy (FTIR) can also be used to confirm the crystalline phases (Fig. S1 and Table S1, ESI $\dagger$ ). All of the peaks reflected from the $(h k 0)$ crystal planes (parallel to $c$-axis) can be clearly seen in both the extruded and hot-pressed films. However, the peaks at $26.6^{\circ}(021)_{\alpha}, 38.9^{\circ}(002) /(131)_{\alpha}$, and (111)/

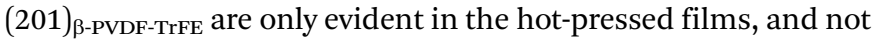
in the extruded films, which highlights the high degree of inplane orientation of $c$-axis (polymer chains) and out-of-plane distribution of $\mathrm{CF}_{2}$ dipole moments in the extruded films. ${ }^{28,29}$

Fig. $1 \mathrm{~b}$ shows the DSC data for the polymer films (summarized in Table S1, ESI $\dagger$ ). The hot-pressed and extruded PVDF films showed similar main melting temperature peaks $\left(\sim 157^{\circ} \mathrm{C}\right)$. The extruded PVDF-TrFE has a sharper Curie transition peak $\left(T_{\mathrm{c}}\right)$ at a higher temperature $\left(\sim 122^{\circ} \mathrm{C}\right)$ compared to HP films $\left(\sim 115^{\circ} \mathrm{C}\right)$, which is consistent with the temperature dependence of dielectric permittivity showing slightly diffuse Curie transition in the hotpressed films but narrower transition peaks in the extruded films (Fig. S2, ESI $\dagger$ ). The $T_{\mathrm{c}}$ of PVDF-based ferroelectric polymers can be predicted from the dipolar energy $\left(W_{\mathrm{D}}\right)$, which is determined by the saturation polarization $\left(P_{\mathrm{o}}\right)$ linked to the dipole moment in a monomer $(\mu)$ and the primitive cell volume at $0 \mathrm{~K}\left(\nu_{0 \mathrm{~K}}\right),{ }^{30}$ as shown in eqn (1), where $\kappa_{\mathrm{B}}$ is the Boltzmann constant.

$$
T_{\mathrm{c}}=\frac{W_{\mathrm{D}}}{\kappa_{\mathrm{B}}}=\frac{\nu_{0 \mathrm{~K}} P_{\mathrm{O}}^{2}}{\kappa_{\mathrm{B}}}=\frac{\nu_{0 \mathrm{~K}}\left(\frac{\sum_{i=1}^{n} \mu_{i}}{\nu_{0 \mathrm{~K}}}\right)^{2}}{\kappa_{\mathrm{B}}}=\frac{\mu^{2}}{\kappa_{\mathrm{B}} \nu_{0 \mathrm{~K}}}
$$

The higher $T_{\mathrm{c}}$ in extruded PVDF-TrFE is ascribed to an enhanced dipole moment arising from a more regular and highly orientated chain packing. ${ }^{6}$ This is confirmed by the morphology characterization and 2D-XRD patterns (Fig. S3, ESI $\dagger$ ), which show that the extruded PVDF-TrFE films exhibited well aligned lamellae, with the polymer chains ( $c$-axis) oriented along the extrusion direction. Similar results were also observed in the extruded blends (Fig. 1b and Fig. S3, ESI $\dagger$ ), with a higher $T_{\mathrm{c}}\left(\sim 128{ }^{\circ} \mathrm{C}\right)$ compared to hot-pressed films $\left(\sim 119{ }^{\circ} \mathrm{C}\right)$. The $T_{\mathrm{c}}$ of the blends is higher compared to pure PVDF-TrFE, suggesting the formation of polar crystals with higher polarity in the blends. ${ }^{31}$

\section{Ferroelectric properties}

Fig. 2 shows the ferroelectric displacement $(D-E)$ hysteresis loops $(10 \mathrm{~Hz})$ of the polymer films along with the original plots of the current-electric field (I-E) loops. The $I-E$ and $D-E$ loops measured at $120 \mathrm{kV} \mathrm{mm}{ }^{-1}$ were used to compare the hot-pressed and extruded films, since the hot-pressed films (thickness: $\sim 80 \mu \mathrm{m}$ ) could only be tested at low electric fields $\left(<130 \mathrm{kV} \mathrm{mm}^{-1}\right)$ due to the limited applied voltage of the ferroelectric tester $(10 \mathrm{kV})$, while the ferroelectric properties of the extruded films can be measured at $320 \mathrm{kV} \mathrm{mm}{ }^{-1}$. Both the hot-pressed and the extruded PVDF films present weak ferroelectric switching at $120 \mathrm{kV} \mathrm{mm}{ }^{-1}$, while the extruded PVDF films show clear ferroelectric switching at $320 \mathrm{kV} \mathrm{mm}{ }^{-1}$ with a remnant polarization $\left(P_{\mathrm{r}}\right)$ of $0.067 \mathrm{C} \mathrm{m}^{-2}$ and a coercive field $\left(E_{\mathrm{c}}\right)$ of $100 \mathrm{kV} \mathrm{mm}^{-1}$ (Fig. 2a). The extruded PVDF-TrFE films show higher switching current density compared to the hot-pressed PVDF-TrFE films at the same field of $120 \mathrm{kV} \mathrm{mm}^{-1}$ (Fig. 2b), which indicates a higher domain wall density in the extruded PVDF-TrFE films linked to their highly ordered chain packing. The extruded PVDF-TrFE shows a $P_{\mathrm{r}}$ of $0.108 \mathrm{C} \mathrm{m}^{-2}$ and an $E_{\mathrm{c}}$ of $50 \mathrm{kV} \mathrm{mm}^{-1}$ at $320 \mathrm{kV} \mathrm{mm}^{-1}$ (Fig. 2b). The higher $P_{\mathrm{r}}$ in the extruded PVDF-TrFE is a result of highly crystalline $\beta$-phase $(\sim 74 \%$ in Table S1, ESI $\dagger)$ compared to the extruded PVDF films $(\sim 42 \%$ in Table S1, ESI $\dagger$ ). Simulation studies reveal that the dipole moment of monomers will experience a 50\% increase when separate chains are put together to build up a crystal due to the local electric field produced by neighbouring chains, ${ }^{32,33}$ which contributes to an enhanced $P_{\mathrm{s}}$. Therefore, the highest values of $P_{\mathrm{r}}$ can be roughly estimated with respect to $P_{\mathrm{s}}$ and degree of crystallinity $(\eta)$ using 

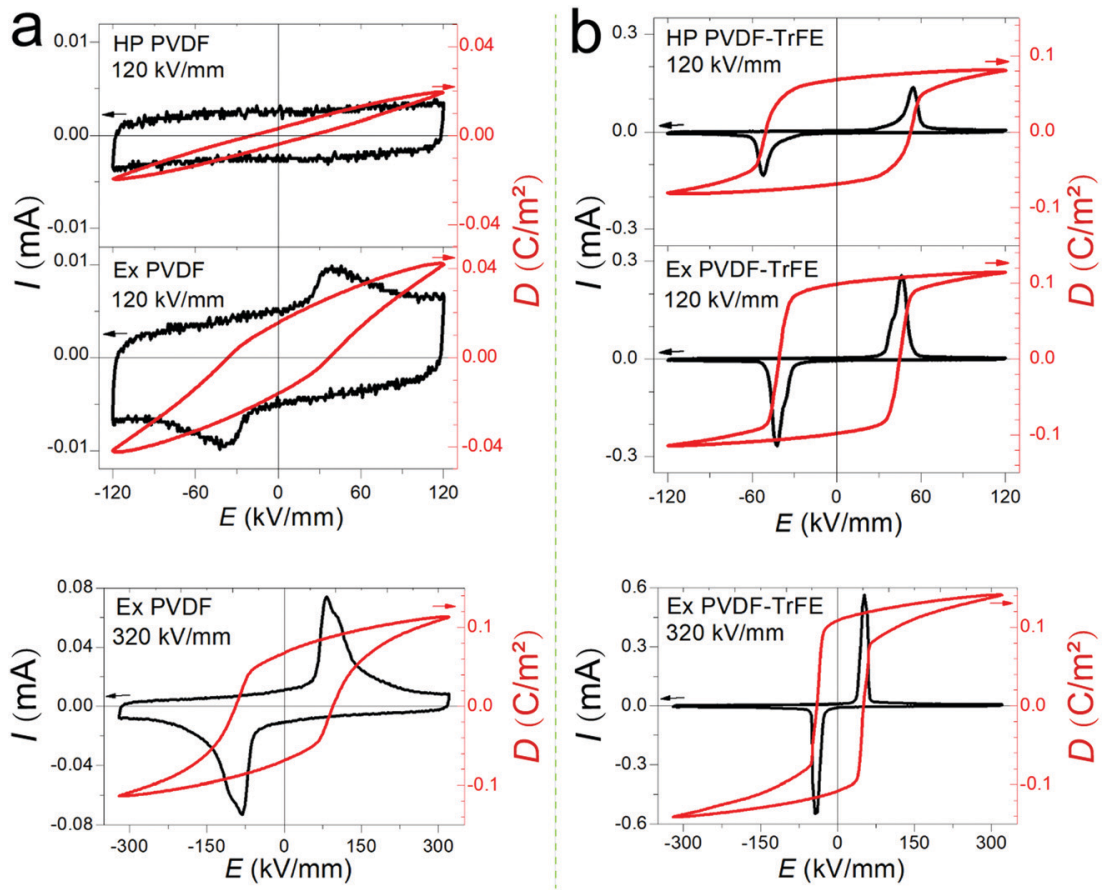
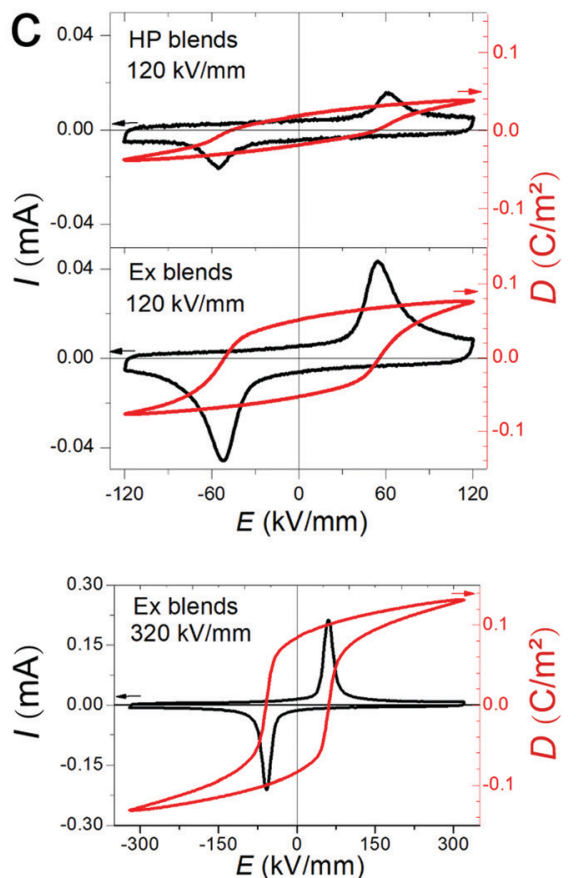

Fig. 2 The ferroelectric properties, current-electric field (I-E) loops and displacement-electric field (P-E) loops measured at $120 \mathrm{kV} \mathrm{mm}^{-1}$ and $320 \mathrm{kV} \mathrm{mm}^{-1}$ of (a) pure PVDF, (b) PVDF-TrFE and (c) 50/50 blended films processed via melt-extrusion (Ex) and hot-compression (HP).

$P_{\mathrm{r}}=P_{\mathrm{s}} \times \eta$, and the values for PVDF and PVDF-TrFE are $0.080 \mathrm{C} \mathrm{m}^{-2}$ and $0.118 \mathrm{C} \mathrm{m}^{-2}$, respectively. These values coincide with the measured values of the extruded films. The high degree of in-plane chain (c-axis) orientation confines the $\mathrm{CH}_{2}-\mathrm{CF}_{2}$ dipole moments in a plane parallel to the external electric field and eases the alignment of dipoles along electric field. The blends show intermediated ferroelectric properties, with a $P_{\mathrm{r}}$ slightly higher than the value of $0.083 \mathrm{C} \mathrm{m}^{-2}$ calculated by rules-of-mixtures.

\section{Frequency dependence of dielectric permittivity}

Fig. 3 shows the frequency dependence of dielectric spectra in the frequency range of $1 \mathrm{kHz}-100 \mathrm{MHz}$ (Fig. 3a-c) and $0.5-2.5 \mathrm{THz}$ (Fig. 3d-f). No difference was observed in the THz-TDS spectra during the $90^{\circ}$ rotation of samples (Fig. S4, ESI $\dagger$ ). The dielectric permittivity is strongly dependent on the frequency of the alternating electric field, being linked to the response time of the different polarization mechanism, which include electronic polarization $\left(10^{15}-10^{18} \mathrm{~Hz}\right)$, vibrational or atomic polarization $\left(10^{12}-10^{15} \mathrm{~Hz}\right.$ ), dipolar orientation polarization ( between $100 \mathrm{~Hz}$ to a few $\mathrm{GHz}$ ) and interfacial polarization. ${ }^{34}$ Below $1 \mathrm{kHz}$, there can be a significant influence of conductivity on the frequency dependence of dielectric permittivity. ${ }^{35}$ Particularly for ferroelectric materials, the spontaneous polarization gives rise to either local polar structures or long range domains, which contributes to the dielectric permittivity. ${ }^{36}$ The hot-pressed PVDF and extruded PVDF films mainly crystallized into $\alpha$-phase, therefore, the dielectric polarization of PVDF $\left(P_{\mathrm{PVDF}}\right)$ can be written as:

$$
P_{\mathrm{PVDF}}=\eta P_{\text {dip.C }}+(1-\eta) P_{\text {dip.A }}+P_{\text {e. }}+P_{\text {at. }}
$$

where $\eta$ is the degree of crystallinity, $P_{\text {dip.c }}$ and $P_{\text {dip.A }}$ are the dipolar orientation polarization in the crystalline and amorphous region, respectively, which are the main contribution of polarization at low frequencies (e.g. $1 \mathrm{kHz}-100 \mathrm{MHz})$, especially $P_{\text {dip.A }}$, since the dipoles in the amorphous regions are highly mobile. $P_{\text {e. }}$ and $P_{\text {at. }}$ are the electronic and atomic polarization in PVDF, respectively, and are not distinguished from crystalline and amorphous regions since they make fairly little contribution to the dielectric permittivity of PVDF. At low frequencies (e.g. $1 \mathrm{kHz}-$ $100 \mathrm{MHz}$ ), all of the $P_{\mathrm{e}}, P_{\text {at. }}$, and $P_{\text {dip. }}$ contribute to the dielectric permittivity. Compared to the hot-pressed PVDF films $(\sim 12$ at $1 \mathrm{kHz}$ ), the extruded PVDF films show larger dielectric constant $(\sim 15$ at $1 \mathrm{kHz})$, which is attributed to the preferred orientation. Polymer chains in the amorphous regions tend to show alignment along the extrusion direction in the extruded films, which is more ideal for dipoles to respond to the vertically applied electric field compared to the completely random chains. ${ }^{37}$

Analogously, the dielectric polarization of hot-pressed and extruded copolymer PVDF-TrFE $\left(P_{\mathrm{co}}\right)$ can be described in eqn (3) with the additional ferroelectric contribution of $P_{\mathrm{s}}$ in the unit cell and the formed local polar structures (LP) containing several unit cells and domain walls (DW) related to long range ordered ferroelectric domains:

$P_{\text {co }}=\eta\left(P_{\text {dip.C }}+P_{\mathrm{s}}+\mathrm{LP}+\mathrm{DW}\right)+(1-\eta) P_{\text {dip. } . \mathrm{A}}+P_{\mathrm{e}}+P_{\text {at. }}$

PVDF-TrFE has smaller content of amorphous region because of its higher $\eta$ and shows relatively low intensity of relaxation loss peak at frequencies from $400 \mathrm{kHz}$ to $100 \mathrm{MHz}$, a relaxation process originating from the dipoles in the amorphous region ( $\alpha_{\mathrm{a}}$ relaxation). ${ }^{37}$ Despite the high $\eta$, PVDF-TrFE exhibit similar dielectric constant compared to PVDF, being ascribed to the additional contribution of $P_{\mathrm{s}}, \mathrm{LP}$ and DW within 

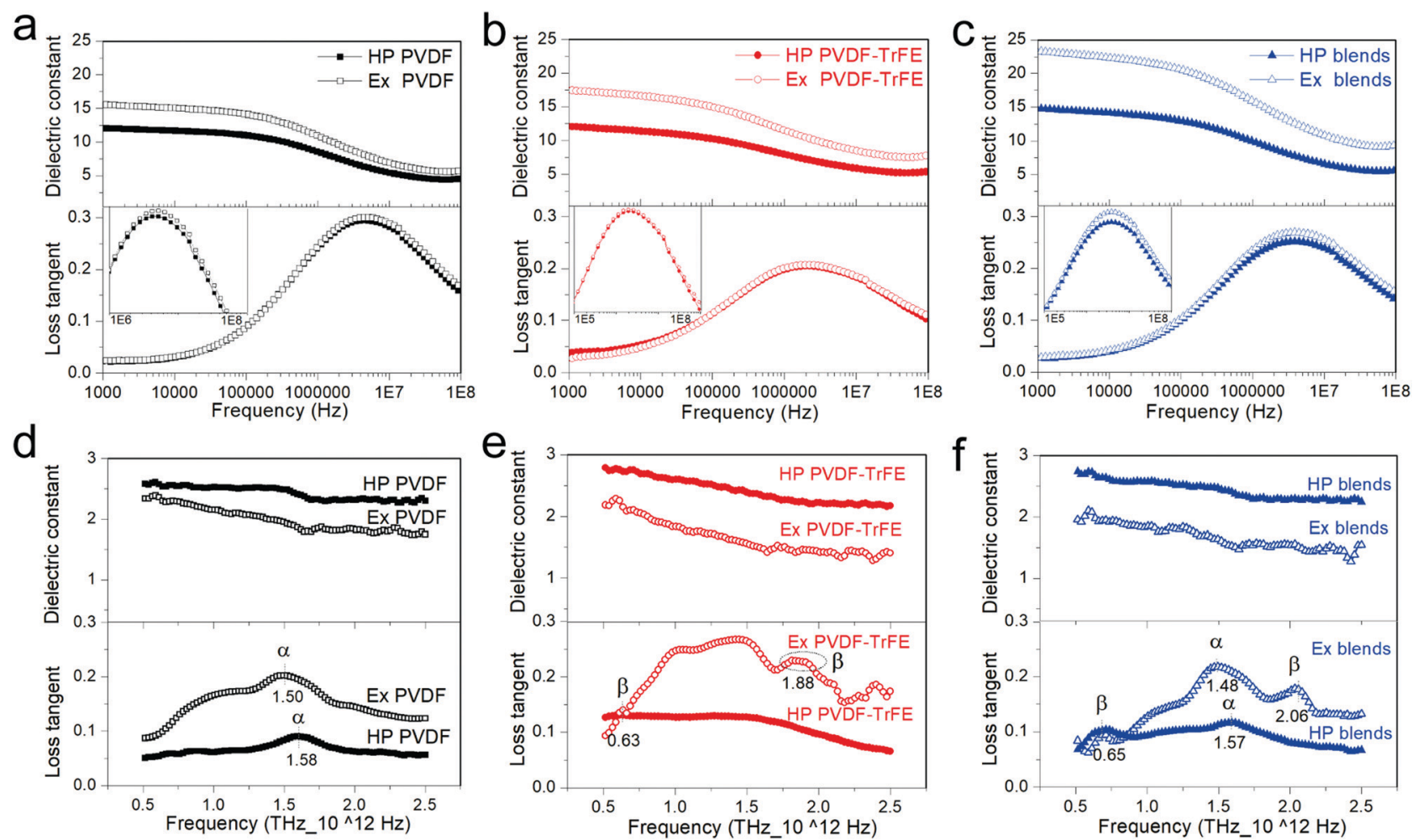

Fig. 3 The frequency dependence of dielectric permittivity from $1 \mathrm{kHz}$ to $100 \mathrm{MHz}$ for: (a) pure PVDF, (b) PVDF-TrFE and (c) 50/50 blended films processed via melt-extrusion (Ex) and hot-compression (HP). The THz-TDS spectroscopy over a spectral domain of 0.5-2.5 THz for: (d) pure PVDF, (e) PVDF-TrFE and (f) 50/50 blended films processed via melt-extrusion (Ex) and hot-compression (HP).

the crystalline regions. A high domain wall density in extruded PVDF-TrFE films, as indicated by the high switching current density (at $10 \mathrm{~Hz}$ in Fig. 2), also contributes to an enhanced dielectric constant.

Compared to pure polymers, the blends show higher dielectric constant, $\sim 15$ for hot-pressed and 22 for extruded films (at $1 \mathrm{kHz}$ in Fig. 3c). Blends have lower $\eta$ and higher $T_{\mathrm{c}}$ compared to PVDF-TrFE (Table S1, ESI $\dagger$ ). A low $\eta$ enhances $P_{\text {dip.A }}$ in the amorphous region. A high $T_{\mathrm{c}}$ is linked to a stronger polar structure that emphasizes the $P_{\mathrm{s}}$ contribution. It is worth noting that for each film, the extruded samples show slightly higher dielectric loss during $\alpha_{\mathrm{a}}$ relaxation ${ }^{18}$ (insets of Fig. 3a-c), which highlights a higher mobility of dipoles in the amorphous region of extruded films.

The dipole relaxation does not occur at frequencies beyond $\mathrm{GHz}$, which explains the low dielectric constant for all of the samples in the $\mathrm{THz}$ region $(\sim 1-3$ in Fig. $3 \mathrm{~d}-\mathrm{f})$ due to the elimination of the $P_{\text {dip.A. }}$. However, $P_{\text {e. }}, P_{\text {at. }}, P_{\mathrm{s}}$ and LP contribute to the dielectric properties of PVDF-TrFE at high frequencies. ${ }^{25}$ The extruded PVDF-TrFE films were chosen as a model to describe the structure and polarization specifications since they crystallize into oriented $\beta$-phase crystals (Fig. 4) and displays lamellae bundle morphology at micro-meter scale, as evidenced by SEM image (Fig. S3, ESI $\dagger$ ), which consists of lamellae crystallites and alternating interfacial and amorphous region. The crystalline lamellae are several microns broad ${ }^{38}$ and 10-50 nm thick. ${ }^{39,40}$ Precise quantitative description of amorphous region remains difficult, however, the thickness of amorphous region is evaluated to be $5-20 \mathrm{~nm}^{39,41}$ It is not reasonable for the transition from ordered crystalline to completely random amorphous region to be abrupt. The thickness of the necessarily existing interfacial region is theoretically expected $^{42}$ and experimentally confirmed ${ }^{43}$ to be 1-3 nm. A high $M_{\mathrm{w}}$, hence averagely longer chains, increases the interfacial free energy related to the crystal basal plane and gives rise to a thicker interfacial region. ${ }^{38}$ Therefore, substantial $P_{\text {dip. }}$ is generated from the interphase or amorphous dipoles. More importantly, the oriented crystals in extruded samples would make some chains in the amorphous region align along the extrusion direction, which enlarges the interfacial region and further enhances the dielectric permittivity at low frequencies $(\mathrm{Hz}-\mathrm{MHz})$. The all-trans chain conformation results in the $\mathrm{CH}_{2}-\mathrm{CF}_{2}$ and $\mathrm{CHF}-\mathrm{CF}_{2}$ dipoles positioning perpendicular to chain backbone (Fig. 4 ) and generating $P_{\mathrm{s}}$ along $b$-axis in a unit cell. The crystalline dipoles are stacked to constitute domains in PVDF-TrFE with an average size of 20-40 nm. ${ }^{44,45}$ The domain walls are reported to be several nano-meters wide. ${ }^{45}$ The polarization reversal of PVDF-TrFE is proposed to be accomplished by the successive $60^{\circ}$ rotation of crystalline dipoles ( $b$-axis) about chain axis ( $c$-axis) with the domain wall progressing through the rotation of molecular chains in the $a-b$ plane of lamellae crystallites. ${ }^{46}$ This highlights the importance of in-plane orientation of chain axis and explains the large polarization of extruded films at high electric fields (Fig. 2). The extruded films 


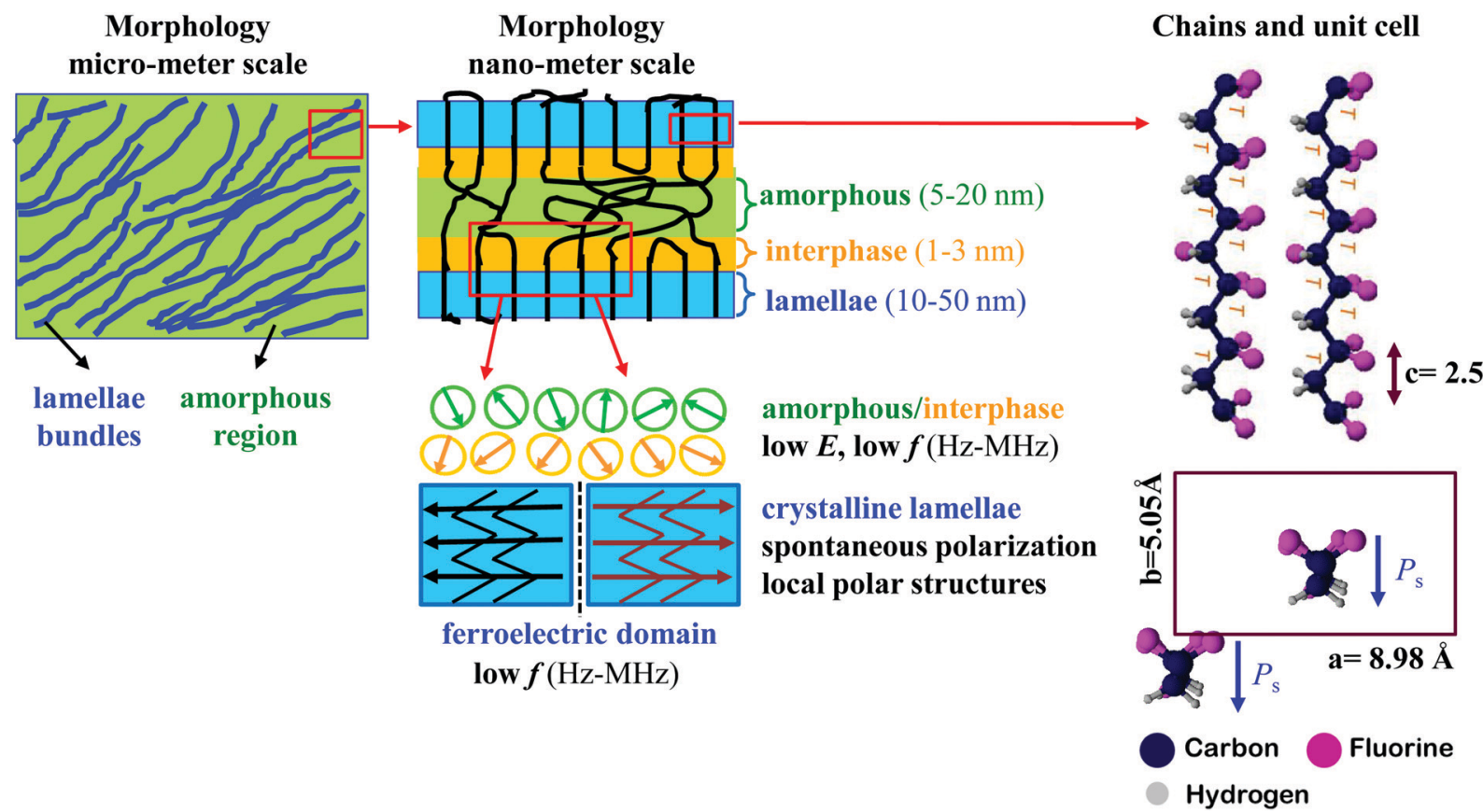

Fig. 4 An illustration of the structure of extruded PVDF-TrFE from micro- and nano-meter scale morphology that consists of crystalline lamellae with amorphous/crystalline interphase and amorphous interlayers to chain configuration and unit cell.

have more defects because of the shear force working on melt flow during processing, which contributes to a higher domain wall density compared to the hot-pressed films and leads to a low coercive field and high dielectric permittivity at low frequencies $\left(\sim 0.1 \mathrm{~Hz}-10^{4} \mathrm{~Hz}\right)$. However, domain walls cannot follow $\mathrm{THz}$ frequencies because of their long relaxation time, ${ }^{47}$ which leads to a low dielectric constant at high frequencies in extruded films compared to hot-pressed films. $P_{\mathrm{e}}$ and $P_{\text {at. }}$ are due to the vibrations of electron or atoms, and they are highly active when the frequency of applied voltage is close to the intrinsic frequency of oscillation ${ }^{34}$ (such as the stretching, torsion, bending, and/or wagging of consecutive chain segments) or libration. ${ }^{48}$ Consequently, the frequency dependence spectra of dielectric permittivity at $\mathrm{THz}\left(P_{\mathrm{e}}\right.$ and $P_{\mathrm{at}}$. dominated $)$ show specific peaks (loss tangent data in Fig. $3 \mathrm{~d}-\mathrm{f}$ ) and can be used as a reference for the phase identification of PVDF-based materials. ${ }^{25}$ The loss peak at about $1.50-1.60 \mathrm{THz}$ is a libration lattice mode in $\alpha$-PVDF. The peaks at $\sim 0.63 \mathrm{THz}$ and $2.10 \mathrm{THz}$ are generally considered as $\beta$-characteristic, which arises from the librational lattice mode around the polymer chain $c$-axis and the pure translation along the crystallographic $a$-axis. ${ }^{49-51}$ PVDF films showed the absence of peaks at $0.63 \mathrm{THz}$ and $2.10 \mathrm{THz}$ due to the main crystallization of $\alpha$-phase. The hotpressed PVDF-TrFE films showed a rather broad feature over the whole frequency range and the extruded films exhibited a weak peak at $0.63 \mathrm{THz}$ and a broad peak at $\sim 1.88 \mathrm{THz}$, which suggests a reduced long distance order of molecular chains, ${ }^{49}$ being a result of a high content of TrFE monomer ( $25 \mathrm{~mol} \%)$. The blends clearly display characteristic $\beta$-PVDF peaks at $\sim 0.65 \mathrm{THz}$ and $2.06 \mathrm{THz}$, which demonstrates that the existence of PVDF-TrFE promotes the formation of $\beta$-phase in PVDF.

\section{Conclusions}

In conclusion, the structure dependent dielectric properties of PVDF-based films were studied using THz-TDS technique combined with impedance analysis. The crystalline structure of films was tailored using different materials - PVDF, PVDF-TrFE and their blends with a mass ratio of 50/50 - and different processing routes - melt-extrusion and hot compression. It was observed that the extruded ferroelectric films possess in-plane orientation of polymer chains, aligned crystalline lamellae and higher domain wall density. This favours the polarization and ferroelectric switching at low frequencies ( $\mathrm{Hz}$ to $\mathrm{MHz}$ ), leading to higher dielectric constants and obvious ferroelectric switching features in extruded films. However, at $\mathrm{THz}$ range $(0.5-2.5 \mathrm{THz})$, the extruded ferroelectric films showed lower dielectric constant compared to hot-pressed films, being a consequence of eliminating domain wall motion at high frequencies. Moreover, the THzTDS spectra clearly show the characteristic peak of $\beta$-PVDF in blended films, which outperforms FTIR and XRD since they cannot distinguish between $\beta$-PVDF and $\beta$-PVDF-TrFE in the blended films.

\section{Conflicts of interest}

There are no conflicts to declare.

\section{Acknowledgements}

The authors would like to thank the financial support of Engineering and Physical Sciences Research Council (EPSRC) (MASSIVE Project, EP/L017695/1) and National Natural Science 
Foundation of China (52073046). Xintong Ren (201606280030) and Dr Jiyue $\mathrm{Wu}$ (201506630005) were financially supported by the China Scholarship Council.

\section{Notes and references}

1 N. R. Alluri, A. Chandrasekhar, J. H. Jeong and S.-J. Kim, J. Mater. Chem. C, 2017, 5, 4833-4844.

2 Q. Li, W. Ke, T. Chang and Z. Hu, J. Mater. Chem. C, 2019, 7, 1532-1543.

3 D. Zabek, K. Seunarine, C. Spacie and C. Bowen, ACS Appl. Mater. Interfaces, 2017, 9, 9161-9167.

4 X. Ren, N. Meng, H. Zhang, J. Wu, I. Abrahams, H. Yan, E. Bilotti and M. J. Reece, Nano Energy, 2020, 72, 104662.

5 Q. Shi, J. Sun, C. Hou, Y. Li, Q. Zhang and H. Wang, Adv. Fiber Mater., 2019, 1, 3-31.

6 Z. Fu, W. Xia, W. Chen, J. Weng, J. Zhang, J. Zhang, Y. Jiang and G. Zhu, Macromolecules, 2016, 49, 3818-3825.

7 S. J. Kang, I. Bae, Y. J. Shin, Y. J. Park, J. Huh, S.-M. Park, H.-C. Kim and C. Park, Nano Lett., 2011, 11, 138-144.

8 A. J. Lovinger, Science, 1983, 220, 1115-1121.

9 T. Furukawa, Phase Trans., 1989, 18, 143-211.

10 N. Meng, X. Ren, G. Santagiuliana, L. Ventura, H. Zhang, J. Wu, H. Yan, M. J. Reece and E. Bilotti, Nat. Commun., 2019, 10, 4535.

11 M. Li, H. J. Wondergem, M.-J. Spijkman, K. Asadi, I. Katsouras, P. W. M. Blom and D. M. de Leeuw, Nat. Mater., 2013, 12, 433.

12 J. Martín, D. Zhao, T. Lenz, I. Katsouras, D. M. de Leeuw and N. Stingelin, Mater. Horiz., 2017, 4, 408-414.

13 R. Gregorio, Jr. and M. Cestari, J. Polym. Sci., Part B: Polym. Phys., 1994, 32, 859-870.

14 M. Wang, S. Wang, J. Hu, H. Li, Z. Ren, X. Sun, H. Wang and S. Yan, Macromolecules, 2020, 53, 5971-5979.

15 S. Barrau, A. Ferri, A. Da Costa, J. Defebvin, S. Leroy, R. Desfeux and J.-M. Lefebvre, ACS Appl. Mater. Interfaces, 2018, 10, 13092-13099.

16 N. Meng, R. Mao, W. Tu, X. Zhu, R. M. Wilson, E. Bilotti and M. J. Reece, Polymer, 2016, 100, 69-76.

17 F. Guan, J. Pan, J. Wang, Q. Wang and L. Zhu, Macromolecules, 2010, 43, 384-392.

18 M. Yuan, B. Li, S. Zhang, R. Rajagopalan and M. T. Lanagan, ACS Appl. Polym. Mater., 2020, 2, 1356-1368.

19 N. Meng, X. Zhu, R. Mao, M. J. Reece and E. Bilotti, J. Mater. Chem. C, 2017, 5, 3296-3305.

20 X. Ren, N. Meng, H. Yan, E. Bilotti and M. J. Reece, Polymer, 2019, 168, 246-254.

21 P. U. Jepsen, D. G. Cooke and M. Koch, Laser Photonics Rev., 2011, 5, 124-166.

22 J. Tang, B. Yang, I. Llewellyn, R. R. Cutler and R. S. Donnan, Chem. Phys. Lett., 2014, 592, 302-306.

23 B. Guzelturk, R. A. Belisle, M. D. Smith, K. Bruening, R. Prasanna, Y. Yuan, V. Gopalan, C. J. Tassone, H. I. Karunadasa, M. D. McGehee and A. M. Lindenberg, Adv. Mater., 2018, 30, 1704737.

24 H. Yan, F. Inam, G. Viola, H. Ning, H. Zhang, Q. Jiang, T. Zeng, Z. Gao and M. J. Reece, J. Adv. Dielect., 2011, 01, 107-118.
25 J. Wu, W. Sun, N. Meng, H. Zhang, V. Koval, Y. Zhang, R. Donnan, B. Yang, D. Zhang and H. Yan, Adv. Electron. Mater., 2020, 6, 1901373.

26 P. Martins, A. C. Lopes and S. Lanceros-Mendez, Prog. Polym. Sci., 2014, 39, 683-706.

27 F.-C. Sun, A. M. Dongare, A. D. Asandei, S. Pamir Alpay and S. Nakhmanson, J. Mater. Chem. C, 2015, 3, 8389-8396.

28 N. Meng, R. Mao, W. Tu, K. Odolczyk, Q. Zhang, E. Bilotti and M. J. Reece, Polymer, 2017, 121, 88-96.

29 R. Mao, N. Meng, W. Tu and T. Peijs, Cellulose, 2017, 24, 4627-4639.

30 J. Lajzerowicz and J.-F. Legrand, Phys. Rev. B: Condens. Matter Mater. Phys., 1978, 17, 1438-1444.

31 E. Bellet-Amalric and J. F. Legrand, Eur. Phys. J. B, 1998, 3, 225-236.

32 S. M. Nakhmanson, M. B. Nardelli and J. Bernholc, Phys. Rev. B: Condens. Matter Mater. Phys., 2005, 72, 115210.

33 J. D. Carbeck, D. J. Lacks and G. C. Rutledge, J. Chem. Phys., 1995, 103, 10347-10355.

34 L. Zhu and Q. Wang, Macromolecules, 2012, 45, 2937-2954.

35 D. P. Almond and C. R. Bowen, J. Phys. Chem. Lett., 2015, 6, 1736-1740.

36 E. Buixaderas, V. Bovtun, M. Kempa, D. Nuzhnyy, M. Savinov, P. Vanek, I. Gregora and B. Malic, Phys. Rev. B, 2016, 94, 054315.

37 L. Yang, J. Ho, E. Allahyarov, R. Mu and L. Zhu, ACS Appl. Mater. Interfaces, 2015, 7, 19894-19905.

38 L. Mandelkern, Acc. Chem. Res., 1990, 23, 380-386.

39 P. J. Flory, D. Y. Yoon and K. A. Dill, Macromolecules, 1984, 17, 862-868.

40 B. Lotz, T. Miyoshi and S. Z. D. Cheng, Macromolecules, 2017, 50, 5995-6025.

41 L. Mandelkern, Faraday Discuss. Chem. Soc., 1979, 68, 310-319.

42 S. K. Kumar and D. Y. Yoon, Macromolecules, 1989, 22, 3458-3465.

43 L. Mandelkern, R. G. Alamo and M. A. Kennedy, Macromolecules, 1990, 23, 4721-4723.

44 P. Sharma, T. J. Reece, S. Ducharme and A. Gruverman, Nano Lett., 2011, 11, 1970-1975.

45 P. Sharma, T. Reece, D. Wu, V. M. Fridkin, S. Ducharme and A. Gruverman, J. Phys.: Condens. Matter, 2009, 21, 485902.

46 T. Furukawa, T. Nakajima and Y. Takahashi, IEEE Trans. Dielectr. Electr. Insul., 2006, 13, 1120-1131.

47 P. S. Bednyakov, B. I. Sturman, T. Sluka, A. K. Tagantsev and P. V. Yudin, npj Comput. Mater., 2018, 4, 65.

48 S. Wietzke, C. Jansen, M. Reuter, T. Jung, D. Kraft, S. Chatterjee, B. M. Fischer and M. Koch, J. Mol. Struct., 2011, 1006, 41-51.

49 M. Latour and R. L. Moreira, J. Polym. Sci., Part B: Polym. Phys., 1987, 25, 1719-1723.

50 M. Kobayashi, K. Tashiro and H. Tadokoro, Macromolecules, 1975, 8, 158-171.

51 M. Latour and R. L. Moreira, J. Polym. Sci., Part B: Polym. Phys., 1987, 25, 1913-1921. 